\title{
Physical Activity During Recess Outdoors and Indoors Among Urban Public School Students, St. Louis, Missouri, 2010-2011
}

\author{
Irene Tran, DPT, MSCI; B. Ruth Clark, PT, PhD; Susan B. Racette, PhD \\ Suggested citation for this article: Tran I, Clark BR, Racette SB. Physical Activity During Recess Outdoors and Indoors \\ Among Urban Public School Students, St. Louis, Missouri, 2010-2011. Prev Chronic Dis 2013;10:130135. DOI: \\ http://dx.doi.org/10.5888/pcd10.130135 圈.
}

PEER REVIEWED

\section{Abstract}

We measured the quantity and intensity of physical activity in 106 urban public school students during recess outdoors, recess indoors in the gym, and recess indoors in the classroom. Students in grades 2 through 5 wore accelerometer pedometers for an average of 6.2 (standard deviation [SD], 1.4) recess periods over 8 weeks; a subsample of 26 also wore heart rate monitors. We determined, on the basis of 655 recess observations, that outdoor recess enabled more total steps per recess period $(P<.0001)$, more steps in moderate-to-vigorous physical activity $(P$ $<.0001$ ), and higher heart rates than recess in the gym or classroom. To maximize physical activity quantity and intensity, school policies should promote outdoor recess.

\section{Objective}

Low physical activity levels contribute to poor physical fitness and are associated with cardiovascular disease risk factors in children $(1,2)$. The 2008 Physical Activity Guidelines for Americans recommends that children engage in at least 60 minutes of physical activity daily, most of which should be moderate-to-vigorous physical activity (MVPA) (3). School-based physical activity has a positive effect on students' health and academic outcomes, particularly among low -income and minority children (4). The objective of this study was to compare the quantity and intensity of physical activity achieved during outdoor and indoor recess among urban elementary schoolchildren.

\section{Methods}

This observational study was conducted from December 2010 through March 2011. Students in grades 2 through 5 attending 2 urban public schools in St. Louis were invited to participate during classroom presentations about the study. Of the 233 invited students, 113 provided oral consent and written parental consent and were enrolled.

Primary outcomes were total steps and steps rated MVPA during recess in 3 locations (outdoors, gym, and classroom) determined using Omron HJ-151 uniaxial accelerometer pedometers (Omron Healthcare, Inc, Lake Forest, Illinois). MVPA was defined as step cadence of 3 miles per hour or more, based on a proprietary Omron formula. Students wore the pedometers at the hip throughout each 20-minute recess period, 2 to 3 times weekly during 3 weeks over an 8week period. Recess choices included free play (eg, jump rope, Frisbee, ball games) and structured activities (eg, hiphop dance, kickball, classroom games, reading), with location dictated by weather conditions and school policy. Research personnel recorded step counts at the recess location after each recess period.

Heart rate during recess was assessed as an estimate of physical activity intensity using Polar E60o heart rate monitors (Polar Electro, Lake Success, New York) in a random sample of 26 students. Heart rate was recorded every 5 seconds and physiologic values (ie, $50-215$ beats per minute $[\mathrm{BPM}]$ ) were averaged.

Health assessments were conducted on 2 occasions and included resting heart rate and blood pressure measured with Omron professional automated monitors (Omron Healthcare, Inc, Lake Forest, Illinois), weight on a digital scale 
(Health-o-Meter, Bridgeview, Illinois), height with a stadiometer (Seca, Birmingham, United Kingdom), and waist circumference at the superior border of the iliac crest. HealthWatch Pro 3.1 software (Seattle, Washington) was used to compute sex- and age-specific percentiles for body mass index (BMI) (5) and waist circumference, and sex-, age-, and height-specific percentiles for blood pressure (6). This study was approved by the Washington University School of Medicine Human Research Protection Office and the school district's Research Review Committee.

Generalized estimating equations with an exchangeable correlation matrix were used to evaluate the effects of recess location and sex on total steps and steps in rated MVPA (SAS version 9.3 [SAS Institute, Inc, Cary, North Carolina]). Analysis of variance was used to compare heart rate between recess locations.

\section{Results}

Of 113 students enrolled in this study, 106 students provided pedometer and health assessment data required for inclusion in the analyses. Participants were $53.8 \%$ female, $88.7 \%$ black, and aged from 7.5 years to 12.3 years (mean, $9.8 \mathrm{y}$, standard deviation [SD], 1.2), with a mean resting heart rate of $88 \mathrm{BPM}$ (SD, 11; range 55-121). Regarding risk prevalence, $9.8 \%$ of participants were classified prehypertensive or hypertensive (blood pressure $\geq 90$ th percentile), $11.4 \%$ were overweight (BMI $\geq 85^{\text {th }}$ and $<95^{\text {th }}$ percentile), $28.6 \%$ were obese (BMI $\geq 95^{\text {th }}$ percentile), and $18.4 \%$ were abdominally obese (waist circumference $\geq 90$ th percentile).

On the basis of 655 recess observations of 106 students (6.2 recess periods per student; SD, 1.4), we determined that the greatest quantity and intensity of physical activity were achieved during outdoor recess. There was a significant interaction between recess location and sex on steps per recess period $(P=.007)$. Girls took an average of 976 steps per recess period outdoors (SD, 385), 692 steps in the gym (SD, 330), and 328 steps in the classroom (SD, 465) $(P<.0001$ for all comparisons) (Figure 1). Boys took 1,281 steps per recess period outdoors (SD, 566), 824 steps in the gym (SD 459), and 378 steps in the classroom (SD, 433, $P<$.001 for all comparisons). Boys accumulated more steps than girls during recess outdoors $(P<.001)$.

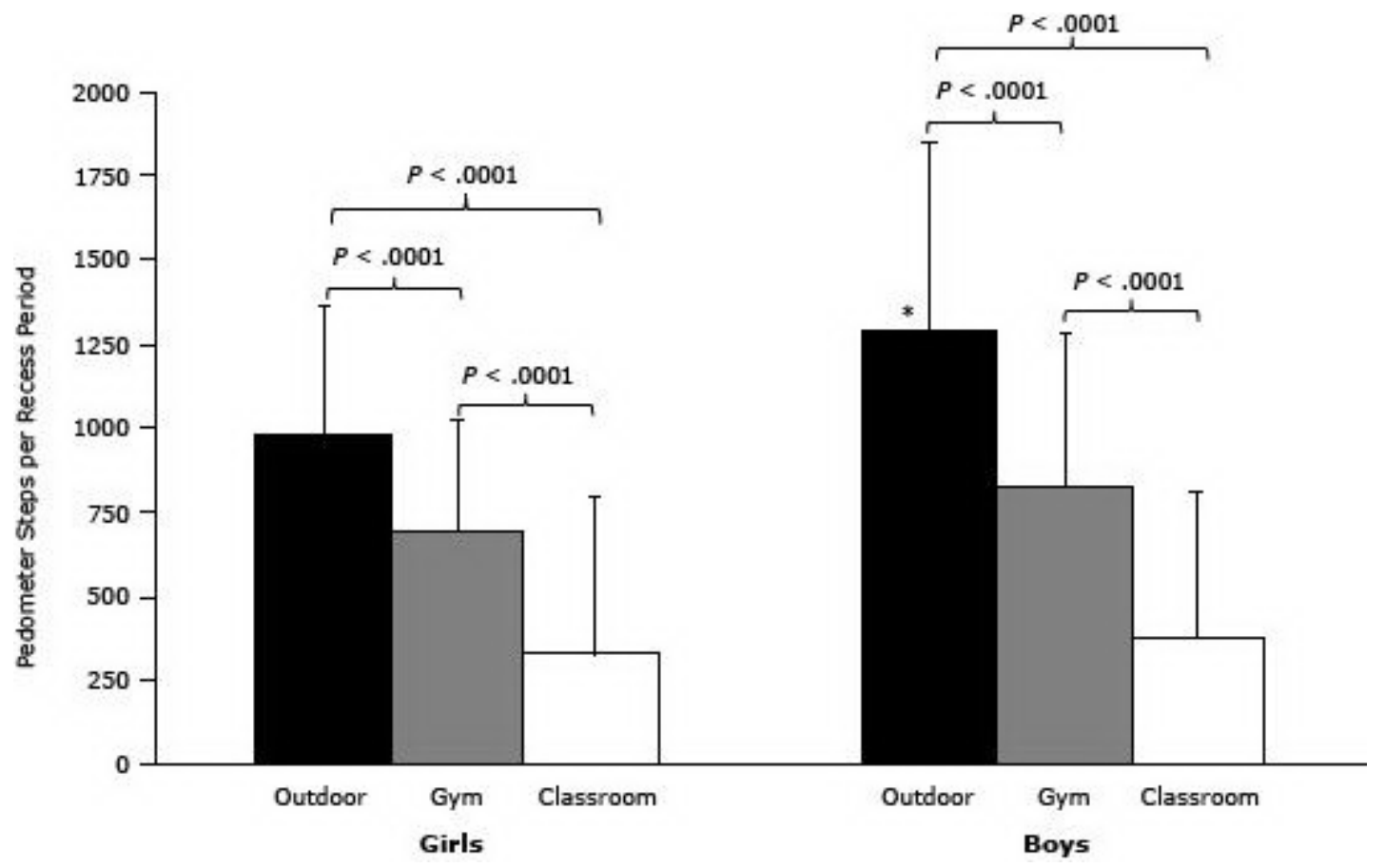

Figure 1. Pedometer-recorded steps by recess location among school students in St. Louis, Missouri, 2010-2011. Bars represent steps per recess period by recess location (mean, standard deviation) averaged across 106 students. The number of recess observations was 291 outdoors, 196 in the gym, and 168 in the classroom. *Boys took more steps during outdoor recess than did girls $(P<.0001)$. [A tabular version of this figure is also available].

More steps during outdoor recess were rated MVPA (56\%) than steps during recess in the gym (36\%) or classroom (15\%) $(P<.001$ across recess locations).

We acquired individual and mean heart rate data for 111 recess observations (4.3 recess periods per student [SD, 2.4] among 26 students) (Figure 2). Average heart rate differed by recess location $(P<.0001): 128$ BPM (SD, 20) outdoors, 118 BPM (SD, 20) in the gym, 97 BPM (SD, 17), in the classroom. 


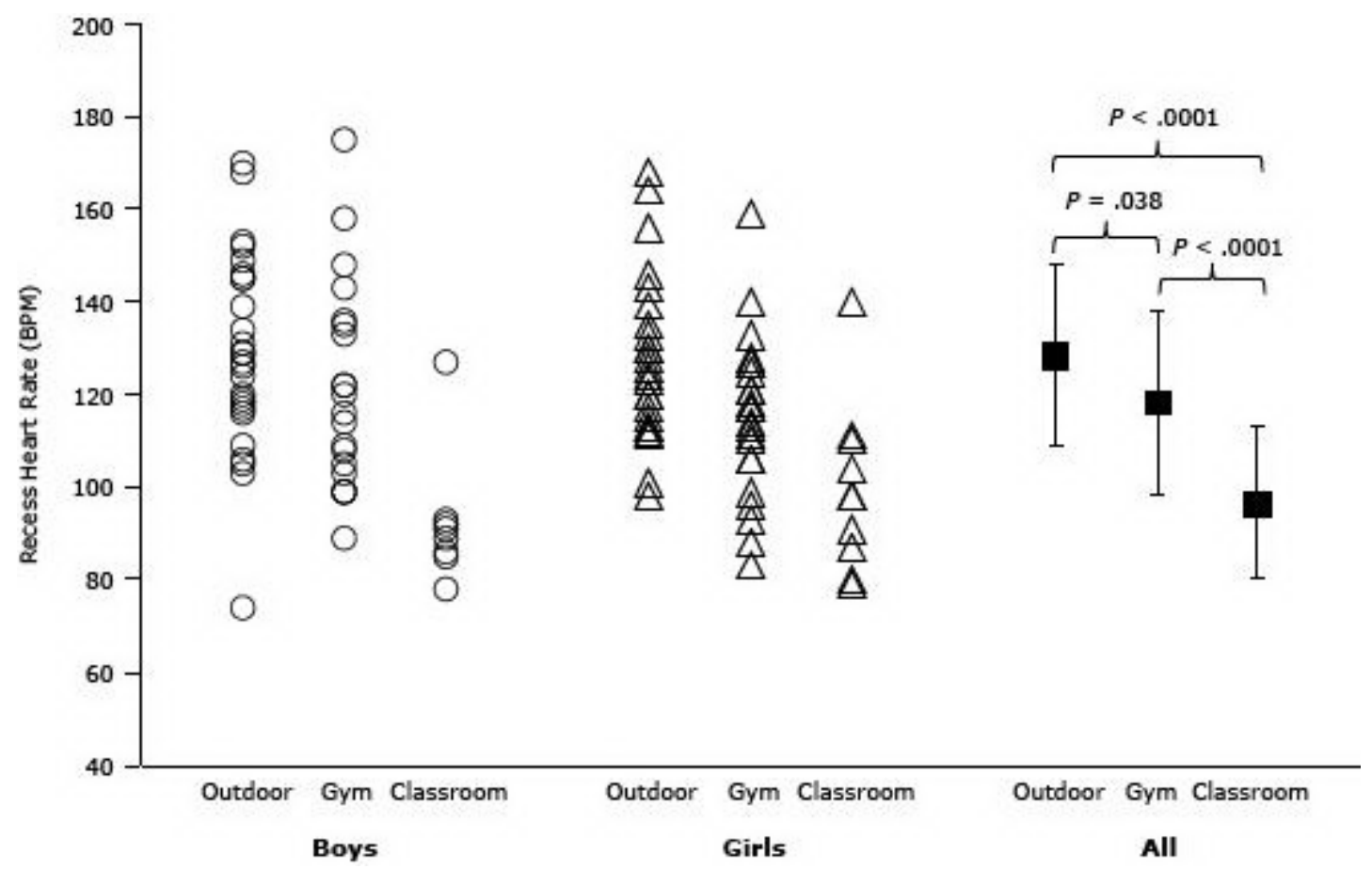

Figure 2. Heart rate by recess location among school students in St. Louis, Missouri, 2010-2011. Each circle and triangle represents a single recess observation (ie, an individual student's average heart rate during a single recess period). Black squares represent the mean and standard deviation heart rate of the 26 students in each location. [A tabular version of this figure is also available.]

\section{Discussion}

Our study revealed that location is a major determinant of the quantity and intensity of physical activity achieved during recess. Students accumulated more total steps and more steps rated MVPA during recess outdoors than during recess in a gym or classroom. Consistent with findings in other studies (7), boys were more active than girls.

High levels of MVPA by children are associated with reduced cardio-metabolic risk factors (8). The Institute of Medicine recommends that schools provide opportunities for students in grades kindergarten through 12 to participate in 60 minutes of physical activity each school day (9). A national sample of children aged 6 to 11 years found that only $42 \%$ achieved the recommended amount of daily physical activity (10). Children who live in low-income neighborhoods may have limited opportunities outside school to engage in physical activity. Reznik et al found that students are more active on school days with a physical education class than on those without and on days with outdoor recess than on those without (11). With physical education curricula limited in many public school districts, recess may account for a large portion of school-based physical activity.

Recess provides students with opportunities for important physical, cognitive, social, and emotional benefits (12). Although our results highlight the importance of outdoor recess to optimize physical activity, indoor recess is often necessary and therefore should include creative activities that promote movement of moderate-to-vigorous intensity, whether in a gym or a classroom (13).

Study limitations are inclusion of only 2 schools and the possibility that study participants were more or less active than nonparticipating students, which would limit the generalizability of our results. Furthermore, accelerometer pedometers provided only estimates of students' MVPA.

In summary, outdoor recess provided the optimal environment for children to engage in quality physical activity. When outdoor recess is not feasible, district and school policies should mandate indoor recess opportunities that promote active play, particularly in urban settings.

\section{Acknowledgments}

This research was funded by grant UL1 RR024992 and TL1 RR024995 from the National Center for Research Resources of the National Institutes of Health, the St. Louis Community/University Health Research Partnerships 
grant, and a Washington University Program in Physical Therapy Research Division Pilot award. We acknowledge the contributions of Michael Kim in conducting the study and thank the student participants and school staff.

\section{Author Information}

Corresponding Author: Susan B. Racette, PhD, Associate Professor, Washington University School of Medicine, Campus Box 8502, 4444 Forest Park Ave, St. Louis, Missouri 63108. Telephone: 314-286-1424. E-mail:

racettes@wustl.edu.

Author Affiliations: Irene Tran, B. Ruth Clark, Washington University School of Medicine, St. Louis, Missouri.

\section{References}

1. Strong WB, Malina RM, Blimkie CJ, Daniels SR, Dishman RK, Gutin B, et al. Evidence based physical activity for school-age youth. J Pediatr 2005;146(6):732-7. CrossRef 圈 PubMed 圈

2. Andersen LB, Harro M, Sardinha LB, Froberg K, Ekelund U, Brage S, et al. Physical activity and clustered cardiovascular risk in children: a cross-sectional study (The European Youth Heart Study). Lancet 2006;368 (9532):299-304. CrossRef 国 PubMed 国

3. US Department of Health and Human Services. 2008 physical activity guidelines for Americans. Washington (DC): Office of Disease Prevention and Health Promotion; 2008.

4. Efrat M. The relationship between low-income and minority children's physical activity and academic-related outcomes: a review of the literature. Health Educ Behav 2011;38(5):441-51. CrossRef 圈 PubMed 圈

5. Kuczmarski RJ, Ogden CL, Guo SS. 2000 CDC growth charts for the United States: method and development. Vital Health Stat 11 2002;(246):1-90. PubMed 国

6. National High Blood Pressure Education Program Working Group on High Blood Pressure in Children and Adolescents. The fourth report on the diagnosis, evaluation, and treatment of high blood pressure in children and adolescents. Pediatrics 2004; 114(2 Suppl 4th Report):555-76.

7. Craig CL, Cameron C, Griffiths JM, Tudor-Locke C. Descriptive epidemiology of youth pedometer-determined physical activity: CANPLAY. Med Sci Sports Exerc 2010;42(9):1639-43. CrossRef 圈 PubMed 圈

8. Holman RM, Carson V, Janssen I. Does the fractionalization of daily physical activity (sporadic vs. bouts) impact

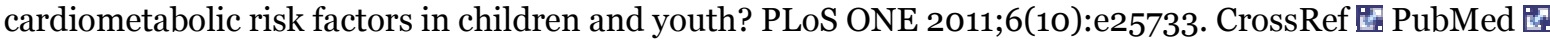

9. Glickman D, Parker L, Sim L, Cook H, Miller E. Accelerating progress in obesity prevention: solving the weight of the nation. Washington (DC): Institute of Medicine of the National Academies; 2012.

10. Troiano RP, Berrigan D, Dodd KW, Masse LC, Tilert T, McDowell M. Physical activity in the United States measured by accelerometer. Med Sci Sports Exerc 2008;40(1):181-8. CrossRef 圈 PubMed 国

11. Reznik M, Wylie-Rosett J, Kim M, Ozuah PO. Physical activity during school in urban minority kindergarten and first-grade students. Pediatrics 2013;131(1):e81-7 and. CrossRef 国 PubMed 圈

12. Murray R, Ramstetter C; Council on School Health, American Academy of Pediatrics. The crucial role of recess in school. Pediatrics 2013;131(1):183-8 and. CrossRef 圈 PubMed 圈

13. Bassett DR, Fitzhugh EC, Heath GW, Erwin PC, Frederick GM, Wolff DL, et al. Estimated energy expenditures for school-based policies and active living. Am J Prev Med 2013;44(2):108-13. CrossRef 国 PubMed 圈

\section{Comment on this article at PCD Dialogue}

Learn more about PCD's commenting policy

The opinions expressed by authors contributing to this journal do not necessarily reflect the opinions of the U.S. Department of Health and Human Services, the Public Health Service, the Centers for Disease Control and Prevention, or the authors' affiliated institutions.

The RIS file format is a text file containing bibliographic citations. These files are best suited for import into bibliographic management applications such as EndNote 专, Reference Manager国, and ProCite 圈. A free trial download is available at each application's web site.

For Questions About This Article Contact pcdeditor@cdc.gov

Page last reviewed: December 05, 2013 
Preventing Chronic Disease | Physical Activity During Recess Outdoors and Indoors Amo... Page 5 of 5

Page last updated: December 05, 2013

Content source: National Center for Chronic Disease Prevention and Health Promotion

Centers for Disease Control and Prevention 1600 Clifton Rd. Atlanta, GA 30333, USA

80o-CDC-INFO (800-232-4636) TTY: (888) 232-6348 - Contact CDC-INFO

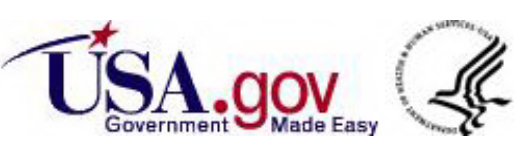

